\title{
Stress decreases host viral resistance and increases Covid susceptibility in embryonic stem cells.
}

Mohammed Abdulhasan

Wayne State University School of Medicine

Ximena Ruden

Wayne State University School of Medicine

Benjamin Rappolee

Washington University In St Louis: Washington University in St Louis

Sudipta Dutta

Texas A\&amp;M School of Veterinary Medicine

Katherine Gurdziel

Wayne State University School of Medicine

Douglas M Ruden

Wayne State University School of Medicine

Awoniyi 0 Awonuga

Wayne State University School of Medicine

Steven Korzeniewski

Wayne State University School of Medicine

Elizabeth E Puscheck

Wayne State University School of Medicine

Daniel A Rappolee ( $\sim$ drappole@med.wayne.edu )

Wayne State University School of Medicine https://orcid.org/0000-0001-9276-7521

\section{Research Article}

Keywords: high throughput screens, embryonic stem cells, hyperosmotic stress, Covid

Posted Date: April 19th, 2021

DOI: https://doi.org/10.21203/rs.3.rs-420961/v1

License: (1) (1) This work is licensed under a Creative Commons Attribution 4.0 International License.

Read Full License 
Version of Record: A version of this preprint was published at Stem Cell Reviews and Reports on June 21st, 2021. See the published version at https://doi.org/10.1007/s12015-021-10188-w. 
To be Submitted to:

Stem Cell Reviews and Reports

472021

\section{Stress decreases host viral resistance and increases Covid susceptibility in embryonic stem cells.}

Mohammed Abdulhasan ${ }^{1,2}$, Ximena Ruden ${ }^{1}$, Benjamin Rappolee ${ }^{3}$, Sudipta Dutta ${ }^{1,4}$, Katherine Gurdziel ${ }^{5}$, Douglas M. Ruden ${ }^{1,6}$, Awoniyi O Awonuga ${ }^{1}$, Steve Korzeniewski ${ }^{6}$, Elizabeth E. Puscheck ${ }^{1,2,8}$, and Daniel A. Rappolee $e^{1,2,6,7,9,10}$

${ }^{1} \mathrm{CS}$ Mott Center for Human Growth and Development, Department of Ob/Gyn, Reproductive Endocrinology and Infertility, Wayne State University School of Medicine, Detroit, Michigan 48201.

${ }^{2}$ Reproductive Stress 3M Inc, Grosse Pointe Farms, MI, 48236.

${ }^{3}$ Washington University of St Louis,63130.

${ }^{4}$ Reproductive Endocrinology and Cell Signaling Laboratory, Department of Integrative Biosciences, College of Veterinary Medicine and Biomedical Sciences, Texas A\&M University, College Station, Texas-77843.

${ }^{5}$ Genome Sciences Center, Wayne State University School of Medicine, Detroit MI, 48201.

${ }^{6}$ Institutes for Environmental Health Science, Wayne State University School of Medicine.

${ }^{7}$ Program for Reproductive Sciences and Department of Physiology, Wayne State University School of Medicine, Detroit MI, 48201.

${ }^{8}$ Invia Fertility Clinics, Hoffman Estates, Illinois 60169.

${ }^{9}$ Department of Biology, University of Windsor, Windsor, ON N9B 3P4, Canada.

${ }^{10}$ To whom correspondence should be addressed at: CS Mott Center for Human Growth and Development, Wayne State University School of Medicine, 275 East Hancock, Detroit MI 48201. E-mail:

drappole@med.wayne.edu

This research was supported by grants to DAR from NIH (1R41ES028991-01, 1R41ES031451-01A1, P30 ES020957, UH3 OD023285, S10 OD025170, CURES Pilot Michigan Emerging Technology Fund).

Current address, Texas A\&M university.

Running title: Stress increases embryonic stem cell Covid susceptibility.

Key Words: high throughput screens, embryonic stem cells, hyperosmotic stress, Covid. 
49 Abstract

Stress-induced changes in viral receptor and susceptibility gene expression were measured in embryonic stem cells (ESC) and differentiated progeny. Rex1 promoter-Red Fluorescence Protein reporter ESC were tested by RNAseq after $72 \mathrm{hr}$ exposures to control hyperosmotic sorbitol under stemness culture (NS) to quantify stressforced differentiation (SFD) transcriptomic programs. Control ESC cultured with stemness factor removal produced normal differentiation (ND). Bulk RNAseq transcriptomic analysis showed significant upregulation of two genes involved in Covid-19 cell uptake, Vimentin (VIM) and Transmembrane Serine Protease 2 (TMPRSS2). SFD increased the hepatitis A virus receptor (Havcr1) and the transplacental Herpes simplex 1 (HSV1) virus receptor (Pvrl1) compared with ESC undergoing ND. Several other coronavirus receptors, Glutamyl Aminopeptidase (ENPEP) and Dipeptidyl Peptidase 4 (DPP4) were upregulated significantly in SFD>ND. Although stressed ESC are more susceptible to infection due to increased expression of viral receptors and decreased resistance, the necessary Covid-19 receptor, angiotensin converting enzyme (ACE)2, was not expressed in our experiments. TMPRSS2, ENPEP, and DPP4 mediate Coronavirus uptake, but are also markers of extra-embryonic endoderm (XEN), which arise from ESC undergoing ND or SFD. Mouse and human ESCs differentiated to XEN increase TMPRSS2 and other Covid-19 uptake-mediating gene expression, but only some lines express ACE2. Covid-19 susceptibility appears to be genotype-specific and not ubiquitous. Of the 30 gene ontology (GO) groups for viral susceptibility, 15 underwent significant stress-forced changes. Of these, $4 \mathrm{GO}$ groups mediated negative viral regulation and most genes in these increase in ND and decrease with SFD, thus suggesting that stressed increases ESC viral susceptibility.

Authors and Funding Sources: DAR: 1R41ES028991-01, 1R41ES031451-01A1, Michigan Emerging Technology Fund and 5P30ES02095707 (Pilot grant). DMR: UH3 OD023285, S10 OD025170and 5P30ES02095707 (Pilot grant). 


\section{Introduction}

The Covid19/2 pandemic has caused trillions of dollars of economic disruption. World-wide, Covid19 infects hundreds of millions and has killed over 450,000 Americans in its first year (https://covid.cdc.gov/coviddata-tracker/\#cases casesper100klast7days). Key elements of a successful Covid19 medical responses are testing, tracking, reducing symptoms, vaccination, and risk analysis of viral effects dependent on susceptibility. An important element of risk analysis is whether environmental toxicants, urban hormonal stresses and nutrition affect susceptibility. Stresses have been linked in a dose-dependent manner to susceptibility through infection under circumstances were host responses and symptoms play a lesser role. ${ }^{1}$

Covid19 is particularly alarming as the newest 3 coronaviruses since 2003 are the most severe: SARS1/Covid1, MERS and the current Covid19/Covid2/SARS2. Coronaviruses have unique dangerous pathogenic features, a large genome of $30 \mathrm{mb}, 3$ open reading frames producing 29 proteins, genomic proof reading capability that maintains pathogenic genomes during replication, and yet the ability to swap genetic sequences and change susceptibility and interactome efficiency ${ }^{2}$ during coinfection of host cells ${ }^{3}$. CoV2 has evolved changes that make it more clinically dangerous than previous coronaviruses. For example, it can infect upper respiratory throat and bronchi and create flu like symptoms or infect lungs and create pneumonia and death. Of the 7 total and 3 severe human coronaviruses (Cov1, Cov2, MERS), only Cov2 infects both the upper respiratory tract and lungs.

It is not surprising that host variation in susceptibility is a lesser focus, but it is still important to understand whether environmental stimuli change host susceptibility including virus uptake and interactome variation. This is especially dangerous in utero where early first trimester, placental syncytiotrophoblasts coexpress TMPRSS2 and ACE2 ${ }^{4,5}$, which are both required for cellular uptake and potential transplacental transfer of virus. Interestingly, it has been reported that human syncytiotrophoblasts (outer placental cells facing maternal circulation) and viruses do not co-express TMPRSS2 and ACE2 ${ }^{6}$ suggesting that early embryos/fetuses and their stem cells are more exposed to Covid19 than stem cells in later fetuses. In addition, the other decidual tissue, extraembryonic endoderm, is also thought to co-express TMRPSS2 and ACE2, where co-expression is necessary for Covid19 virion uptake ${ }^{4,7}$. Thus, the two membranes between the embryo/fetus and maternal virus, may both take up the virus and expose embryonic stem cells and/or derivative differentiated lineages. If stress increased Covid19 susceptibility genes and decreased viral resistance genes, lytic cell death in the early embryo 
could be loss before detection of placental hormones and would not be recorded as a miscarriage. Occult losses or the stress-induced epigenetic memory of survival of early ESC lineage cells could lead to lineage imbalance or epigenetic error affecting the life of the placenta, yolk sac and neonate.

From the host cell perspective, a small number of genes is needed for cellular binding and uptake of the Cov2 virion. Throughout the host cells are protein interactomes, which can be targeting to enable drug repurposing, but also yield markers identifying susceptible cells ${ }^{2,8-10}$. Key markers for susceptibility are a small set of genes binding receptors and fusigenic proteinases that clip the receptor and enable membrane fusion; cell surface and receptors - ACE2 human $\beta$ Cov1/2), Anpep and Anpep ( $\beta$ Cov2 co-receptor candidate) ${ }^{11}$, DPP4 (MERS $\beta$ Cov), and fusigenic serine proteases; TMPRSS2 ( $\beta \operatorname{Cov1/2),~Cathepsins~b/l~(Ctsb,~Ctsl),~Furin~(~} \beta$ Cov1/2), Vim ${ }^{12}$.

There is a general knowledge of viral susceptibility genes, but also specific reports that ESC have antiviral responses and several groups of genes are necessary for these responses; histone chaperones, sumoylation factors, and chromatin modifiers which prevent proviral transcriptional activity ${ }^{13,14}$. It is important to test whether known ESC viral resistance genes change expression during normal or stressed stemness or early differentiation. Gene ontology groups are a means to test host viral interactions, especially negative regulation or resistance by host, in larger interacting gene sets ${ }^{15}$.

We report here that nearly all these markers increase with normal ESC differentiation and increase further still with stress, and that viral resistance (i.e., negative regulatory) gene GO Groups increase with normal differentiation but decrease with stress. Taken together these transcriptomic changes, if accompanied by proteomic changes, would lead to greater viral infection in earliest cells in the ESC lineage, probably XEN lineage cells, which are essential for embryonic survival by the start of gastrulation, two days after the embryo implants into the uterus ${ }^{16}$. 


\section{Materials and Methods}

\section{Materials}

Germline competent mESC-D3 cells were purchased from ATCC (Manassas, VA). DMEM medium was obtained from HyClone (Logan, UT). Gibco ${ }^{\mathrm{TM}}$ glutamax and sodium pyruvate supplement solutions were from Life Technologies (Grand Island, NY). ESC-qualified EmbryoMax fetal bovine serum, $0.1 \%$ gelatin solution and ESGRO ${ }^{\mathrm{TM}}$ Mouse LIF medium supplement were from EMD Millipore (Billerica, MA). Rex1 promoter reporter that enables expression of red fluorescent protein mApple were from Allele Biotechnology (San Diego, CA) as described previously ${ }^{17,18}$. MEM non-essential amino acid solution, sorbitol, 2-mercaptoethanlol and other chemicals were from Sigma (St. Louis, MO). QIAzol Lysis reagent for mRNA isolation was from QiaGen (Ann Arbor, MI)

\section{Embryonic stem cell culture and RNA preparation}

Rex1-RFP embryonic stem cells were cultured as described previously ${ }^{17,18}$. Rex1-RFP ESCs were optimized at passage for exponential growth during the stimulus period, which began $18 \mathrm{hr}$ after passage at $24 \%$ confluence. Germline competent mESC-D3 cells (ATCC, Manassas, VA) from Doetschman et al ${ }^{19}$ were cultured in the absence of feeder cells in DMEM (Gibco, Grand Island, NY ) supplemented with 15\% mESC-screened fetal bovine serum (HyClone, Logan, UT ), 2mM L-glutamine, 1mM sodium pyruvate, $1 \mathrm{mM}$ nonessential amino acids, $0.1 \mathrm{mM}$ 2-mercaptoethanol (Sigma, St. Louis, MO), and $1000 \mathrm{U} / \mathrm{mL}$ murine leukemia inhibitory factor (LIF; Millipore, Temecula, CA) on $0.1 \%$ gelatin-coated dishes at $37^{\circ} \mathrm{C}$ in humidified air with $5 \% \mathrm{CO}_{2}{ }^{20}$. mESCs were cultured overnight after passaging before stimulation with sorbitol. Osmolality of ESC media with and without added 200-300mM sorbitol was determined previously ${ }^{21}$. ESC were washed at Tfinal and lysed using Trizol.

\section{RNA isolation, cDNA library prep, and RNAseq}

RNA expression analysis was done by the Wayne State University Applied Genomics Technology Center with the following method. An aliquot of the RNA was assessed by microfluidics using the ScreenTape for the Agilent 2200 TapeStation. The electrophoretogram, RNA Integrity Number (RIN), and the ratio of the 28S:18S RNA bands were optimized for overall quality of the RNA as done previously. RNA-seq was used to determine expression profiles. Lexogen's QuantSeq 3'mRNA-seq Library Prep Kit (FWD for Illumina) will be utilized for building RNA-seq libraries from $0.1-200 \mathrm{ng}$ of total RNA in $5 \mu \mathrm{l}$ of nuclease-free ultrapure water. Libraries will be quantified on the Qubit and Agilent 2200 Tapestation using the DNA High Sensitivity Screen tape. The barcoded 
160 libraries were multiplexed at equimolar concentrations and sequenced on an Illumina NovaSeq 6000. Data were

161 demultiplexed using Illumina's CASAVA 1.8.2 software. After quality was assessed ${ }^{22}$, and reads were aligned

162 to the mouse genome (Build mm9) ${ }^{23}$ and tabulated for each gene region ${ }^{24}$. Differential gene expression analysis

163 was used to compare transcriptome changes between conditions ${ }^{25}$. Significantly altered genes (log fold change

$164 \geq 2 ;$ FDR $\leq 0.05$ ) were used to identify affected pathways ${ }^{26}$.

165 Statistics

166 Data from at least three independent biological experiments were analyzed using Microsoft Excel and presented

167 as means \pm SEM. Statistical analysis was done by student $t$-test. Geometric means analysis was used in the

168 fluorescent flow cytometry study; the brightness of the fluorescent labeled cells ranges from low-to-high over a

169 logarithmic range of fluorescence axis. This feature of fluorescent flow cytometry fits this criterion of geometric

170 mean quantification, where higher reliability and repeatability were achieved than arithmetic mean quantifica-

171 tion $^{27}$. 
Results

The experimental protocol used a $72 \mathrm{hr}$ stimulus of ESC to normal stemness (NS) with stemness and proliferation-maintain Leukemia inhibitory factor (LIF), normal differentiation by LIF removal (ND), and three levels of hyperosmotic stress as a positive control of stress-forced differentiation (SFD) used in previous studies (Figure ${ }^{18,21,28}$ ). The $72 \mathrm{hr}$ stimulus was previously established for use with Rex1-RFP ${ }^{17,18}$ and Pdgfra-GFP28 transgenic ESCs as it enables some differentiation and a 2-3fold change in stemness and $1^{\text {st }}$ differentiated lineage, respectively. Dose of 200, 250 and $300 \mathrm{mM}$ sorbitol creates reduced growth, near zero growth, and negative growth, respectively. But, at highest dose initial death occurs only in the first $12 \mathrm{hr}$ and by $72 \mathrm{hr}$ there is approximately $5 \%$ death (data not shown, ${ }^{21}$ ), enabling assay of robust levels of stress responses where highest stimulusresponse is induced. Comparisons are first used to test for significant and high fold change $(F C)$ differences between ND from NS and then how SFD differs from ND. The final comparison is between SFD and NS to test how stress induces changes from the starting state of NS or naïve pluripotency equivalent to the source of ESC in the inner cells mass of the preimplantation embryo within 4.5 days of fertilization ${ }^{29-32}$.

In Figure 2A, the majority of XEN $1^{\text {st }}$ differentiated lineage genes from two previous reports ${ }^{33,34}$ increased in cultured ESC here with ND (green box) with LIF removal but also increased more during exposure to $300 \mathrm{mM}$ sorbitol mediated SFD (red box) despite LIF. All other lineages reverse directions between increase in ND/NS and decrease in SFD/ND. Originating $0^{\text {th }}$ lineage/Naïve pluripotency decreased with ND/2 ${ }^{\text {nd }}$ lineage (to primarily formative pluripotency data not shown ${ }^{35}$ ) and increased with SFD. Also, primed pluripotency/ $3^{\text {rd }}$ lineage increased with ND and decreased with SFD. In Figure 2B, most genes in 4 different viral GO group processes increase during ND compared with NS and decrease during SFD compared with ND. In Figure 2C, the majority of Covid19 or Covid1/MERS receptor genes increase with SFD compared with ND and ND more than NS in a manner like $1^{\text {st }}$ lineage XEN increase in Figure 2A. Most single viral susceptibility genes increase with ND and SFD whether this is significant. Since TMPRSS2 is specific to endoderm and increases with ND and SFD are XEN, this suggests that stress may increase viral susceptibility by transdifferentiating ESC to XEN despite LIF presence. Figure 2D shows the three sequential stages of embryogenesis, before and after implantation, and the lineage number assignments in temporal sequence as naïve pluripotency restricts to formative and then primed pluripotency at the start of gastrulation. 
In Figure 3 basal counts for coronavirus susceptibility genes in ESC culture under NS/naïve conditions tend to be at low levels, as for most transplacental viruses, suggesting low susceptibility in stem cells under naïve pluripotent culture, but a possible expression in subpopulations of cells in heterogeneous culture. Only one gene, Vim is expressed above 10counts in the Coronavirus receptor/susceptibility gene group, whereas 3 genes, Pvrl1, Pvr and Hn1 are expressed above 10counts in transplacental viruses. After LIF removal for $72 \mathrm{hr}$ as ESCs begin the transit from Naïve pluripotency (NS) to Formative pluripotency (ND) and other subpopulations arise, most viral susceptibility genes upregulate (10/15) but no gene expression FC are significant. However, comparing ND to SFD highest dose at $300 \mathrm{mM}$ sorbitol stress $8 / 15$ genes have significant FC by Pvalue and/or FDR 10/15 genes upregulate. All 3 of the host coronavirus susceptibility genes that are significant in SFD FC are upregulated (Tmprss2, VIM, DPP4) and 2/5 of the other genes, mostly transplacental virus susceptibility genes are upregulated (Havcr1, Pvrl1).

We analyzed total counts of mRNA for 20 viral receptors [ ${ }^{36}$ Chapter on Biology of Viruses and Viral Diseases James D. Chappell and Terence S. Dermody] ${ }^{36-39}$ in ESCs cultured under 1) NS conditions and then FC changes from NS to 2) ND or 3) $300 \mathrm{mM}$ sorbitol highest SFD to elucidate viral susceptibility under these three conditions. Supplemental table 1. Eight of twenty viruses had > 10 mRNA counts/cell during NS culture. In rank order these were the GNB2L1 > Rpsa > Ldlr > Pvrl2 > Cul5 > Icam1 > vim > Pvrl1 genes which are receptors for these viruses, respectively; influenza A > Sindbis > Rhino minor sero group > herpes $2>$ encephalomyocarditis $>$ Rhino major sero group > Covid2 > Herpes 1. The highest upregulated genes/viral receptors with ND were CR2/Epstein Barr and Anpep/several mammalian corona viruses. The highest downregulated genes/viral receptors with ND were CD4/HIV and Tnfrsf23/Pseudorabies. But the FC for all up- and down-regulated genes were not significant (pValue or FDR). The highest upregulated genes/viral receptors for 300mM sorbitol SFD were Havcr1/hepatitis A, Tnfrsf23/Pseudorabies, Pvrl1/Herpes 1, and Vim/Covid2. Havcr1, Pvrl1, and Vim were all significant for pValue and FDR. The highest downregulated genes/viral receptors for 300mM sorbitol SFD were CR2/Epstein-Barr and Cd4/HIV, but none of these were significant.

Pdgfra-GFP ESC intermediate and bright subpopulations mark $1^{\text {st }}$ differentiated lineage XEN cells, assayed by flow cytometry increased with increasing sorbitol above 300 to $400 \mathrm{mM}$ sorbitol, despite LIF presence (Figure 4A). Only minor increases in intermediate bright Pdgfra+ cells at 200-250mM sorbitol. Interestingly, 300mM sorbitol despite LIF produced almost equal increases in Pdgfra+ intermediate and bright cells as retinoic 
acid at 1 uM with LIF removal an established inducer of XEN cells ${ }^{28,40}$. Since retinoic acid at this level is a normal morphogen for XEN cells ${ }^{40}$, this suggests that $300 \mathrm{mM}$ overrides LIF and forces differentiation of a subpopulation of ESC.

Stress increases Covid19 susceptibility genes that are markers of $1^{\text {st }}$ lineage XEN cells and their derivative extraembryonic endoderm lineages (Figure 2,3 ) and induces $1^{\text {st }}$ lineage as shown here and previously $21,28,41$ . We thus surveyed mouse and human ESC and derivative XEN lineage differentiation at NCBI GEO profiles for expression of covid19 susceptibility genes TMPRSS2 and ACE2 and the XEN determining factor at the time of lineage allocation in the blastocyst, Gata6, which is essential in XEN lineage allocation in the blastocyst ${ }^{42,43}$. All three genes were expressed at low or nil levels in undifferentiated embryonic stem cells but increase in some or all lineages of mouse or human XEN cells (Figure 4A, B). There was apparent heterogeneity in XEN differentiation and covid19 expression in different genetic backgrounds or due to other elements of quality of cell lines.

Of 15 significant changing host viral GO groups, 14 reverse most of their genes' expression from ND/ND to SFD $300 \mathrm{mM} / \mathrm{ND}$ with 13 increasing with ND and decreasing with SFD and 1 decreasing with ND and increasing with SFD (Figure 5A). One GO group increased with ND and SFD. Rank of significance was higher during SFD>ND for all $15 \mathrm{GO}$ groups. Significance was rare for ND/NS and only $4 / 15$ groups were significant changed but for SFD/ND all 15 groups changed significantly.

There are approximately 300 host viral interaction GO groups amongst approximately 45,000 groups ( https://www.ebi.ac.uk/QuickGO/searchterms/viral, https://en.wikipedia.org/wiki/Gene ontology\#Terms and ontology). In ESC, there were 92 genes in the 15 significant host viral response GO groups which are listed at the top of Supplemental Table 2. At the bottom of the table, are two auxiliary tables that show how the 92 genes are shared amongst all 15 groups and amongst the 4 negative regulatory groups. In the four negative regulatory groups the most common expressed genes in 3/4 groups are - jun, tetherin (aka Bst)2, and Interferon-induced transmembrane protein 1 (Ifitm1), and 4/4 groups are - 2'-5'-oligoadenylate synthetase 1 (Oas1b), Tripartite motif-containing 28 (Trim28), and Interferon-stimulated gene 15 (Isg15). Most of these have antiviral activities and some have known function in pluripotent cells. For all 15 groups the most commonly expressed gene are; in 11/15 groups; oas1b and Isg15, in 9/15 groups; TRIM28, and in 7/15 groups; Krüppelassociated box zinc finger protein (Zfp)809, Ifitm1, Nucleoporin 93 (Nup93), and nucleotide-binding oligomerization domain, leucine rich repeat containing X1 (NIrx1). 
At the other end of the expression spectrum are 22 genes expressed in only one GO group. Of these 22,9 are of great interest because there is high counts and high and significant fold change in 2-3 of 3 possible comparisons; ND/ND or SFD/ND or SFD/NS. These 9 are Tmprss2, Proenkephalin (Penk), Basic leucine zipper transcription factor, ATF-like (Batf3), Myeloid differentiation primary response 88 (Myd88), Mitogen-activated protein kinase 11 (MAPK11, aka p38MAPKß), heat shock protein beta-1 (Hspb1, aka HSP27), THO complex subunit 6 homolog (Thoc6), alpha-actin-2 (Acta2), and Autophagy Related 16 Like 2 (Atg16l2).

The highest dose at $300 \mathrm{mM}$ is a "demonstration dose" with highest fold change and significance, but so harsh in decreasing cell number during $72 \mathrm{hr}$ exposure, that this would be too morbid a dose to consider as affecting normal development. We thus assayed the lowest dose at $200 \mathrm{mM}$ sorbitol for which of the significant doses at $300 \mathrm{mM}$ were also affected significantly and found that only $5 / 15$ host viral response GO groups were affected. Of the GO groups significantly changed at $200 \mathrm{mM} 4 / 5$ are in the top 5 most significant. Interestingly, of the $15 \mathrm{GO}$ groups for host viral genes that had insignificance and lack of large change in ranking between unstress and stress groups at 300mM sorbitol (Figure 5B), the only directional regulatory were for 3 positive GO groups.

To confirm even expression of ESC cultured with 5 stimuli, 2 unstressed NS and ND (naïve and formative pluripotency, respectively), and 3 stressed (200mM, 250mM, and $300 \mathrm{mM}$ sorbitol) we tested for even expression with non-significant FC between stimuli and with low FC below 1.4. This was done by assaying the top twenty expressed genes at $300 \mathrm{mM}$ determined here and by using previous reported loading control $^{44-46}$ (Figure 6A, B). For the top 20 highest expressed genes here, 13 are expressed at high stoichiometry in ribosomes, related to RNA loading controls in past studies of stress forced expression changes in mouse $\mathrm{ESC}^{17,18,21,28}$, but one of these had high and significant FC between NS and SFD (Figure 6A). Of the 7 other highest expressed nonribosomal genes, only Tuba1b was also disqualified for high FC and significance. For more traditional loading controls, only Hprt was disqualified as a loading control for FC>1.4 and significance, but several other genes had FC>1.4 without significance (Gapdh, PGK1, B2M, Ppia, Hmbs) (Figure 6B). Altogether, the data from ribosomal, other highest expressed, and traditional loading controls suggest that total mRNA counts, and genes expressed per cell are well supported. 


\section{Discussion}

We report here that studies of single host viral susceptibility genes and several GO groups of host viral response and interaction genes change with stress that increases viral Covid19 susceptibility specifically as well increasing susceptibility to as all viruses in general.

The culture model for ESC exposure used here replicated previous $72 \mathrm{hr}$ exposures used to test for stress effects on Rex1-RFP $0^{\text {th }}$ lineage NS or naïve pluripotency loss ${ }^{18}$ and Pdgfra-GFP $1^{\text {st }}$ differentiated lineage XEN gain $^{28}$ and the sorbitol doses of 200,250 and $300 \mathrm{mM}$ yield reduce but positive growth, near nil growth, and negative growth through initial apoptosis and chronic adaptation, respectively.

Most coronavirus susceptibility genes increase when NS differentiates to ND without stress by LIF removal and increase more when SFD at $300 \mathrm{mM}$ expression is compared with ND. In addition to increase to susceptibility due to single gene increases, the majority of all 4 negative regulatory GO groups increase with NS to ND, putatively suppressing viral processes. But most genes reverse and decrease expression with SFD compared with ND, suggesting that viral susceptibility due to stress-forced loss of resistance would exacerbate the coronavirus effects after entrance into the host cell. Taken together, stressed ESC express increased Covid receptors and decreased negatively regulatory GO groups genes, which may be pathogenically synergistic. But does this occur in the stressed ESC themselves or in stress-forced differentiation to $1^{\text {st }}$ lineage.

Several lines of evidence suggest that XEN cells differentiated from ESCs may be the primary candidate cell for Covid19 infection. Several Covid19 genes are known to be expressed by XEN cells: TMPRSS ${ }^{47}$ and DPP4 are expressed mostly by XEN visceral lineage ${ }^{48,49}$, ENPEP is expressed by mostly XEN ${ }^{50}$, and VIM is expressed mostly by XEN parietal endoderm ${ }^{51}$. Thus, the induction of coronavirus is associated with the induction of XEN lineages. These covid susceptibility genes are expressed mostly at exceptionally low levels in the NS/Naïve pluripotency starting state but increase with ND and more with SFD compared to NS. This suggests that low levels of these genes are expressed in naïve ESCs during NS culture but an induction of a small subpopulation of $1^{\text {st }}$ lineage endoderm.

Flow cytometry was performed to test for stimulation induced increase from NS naïve pluripotency to ND formative pluripotency and to test for $1^{\text {st }}$ subpopulation size increase in XEN. There was a large increase to an intermediate bright Pdgfra-GFP subpopulation of $\sim 20 \%$ and smaller bright subpopulation of $\sim 1 \%$ with $300 \mathrm{mM}$ sorbitol despite LIF and this was equivalent to the normal $1^{\text {st }}$ lineage XEN inducer retinoic acid with LIF removal 
${ }^{40,49}$. But a key deficit of induction of covid19 susceptibility by stress was the lack of ACE2 in mouse ESC tested here in NS ND or SFD 300mM sorbitol. Both mouse and human ESC lines produce ACE2 and TMPRSS2 genes necessarily co-expressed for covid19 uptake after induction of XEN by cultural manipulation of mouse $\mathrm{ESC}^{52}$ or transgenic overexpression of genes in human ESC, sox 7 or sox $17^{53}$. But not all mouse or human ESC lines expressed high levels of ACE2 suggesting genetic heterogeneity or some other deficit in inducing a full susceptibility interactome.

Stress increases significance of 15 viral host response GO groups and an increase in rank of significance from ND to SFD. Highest increases in rank are over 10 fold from $64 \%$ to $5.9 \%$, but the most interesting are two that increase significantly from NS to ND and decrease significantly from SFD compared with ND. The least change is $47.2 \%$ to $32.8 \%$ (viral genome replication). but this is also a reversal from majority gene expression increase to majority decrease. Only one significant GO group does not undergo a reversal and it increases from 98.3 to $32.8 \%$ ranking from ND to SFD (regulation of defense of host to virus). Two GO groups are not listed in any pairwise comparison and are unranked but are highly significant, with $20.0 \%$ and $23.6 \%$, for SFD $300 \mathrm{mM}$ sorbitol compared to ND.

Six of the most shared genes are expressed in 3 or 4 of the four negative regulatory GO groups mediating viral resistance and $5 / 6$ of these genes have been reported to mediate viral resistance. Individual genes expressed in 3 of 4 of the negative regulatory host viral response GO groups are of great interest. Jun, Bst2 and Ifitm1 are expressed in three of the four groups. Jun is a stress transcription factor implicated in the stress response of ESC, TSC and early embryos. ${ }^{54}$ Bst2, also known as tetherin is a protein associated with plasmalemma lipid rafts and has been reported to inhibit retrovirus by preventing viral particles' diffusion into infected cells. ${ }^{55} \mathrm{Ifitm} 1 / 3$ is Interferon-induced transmembrane protein 1. IFITM proteins are antiviral restriction factors for influenza A virus replication, probably at the early step of life cycle such as cellular entry and membrane fusion. 56

Individual genes expressed in 4 of 4 of the negative regulatory host viral response GO groups are also of great interest. Oas1b or 2'-5'-oligoadenylate synthetase 1 is an enzyme that is important in the innate immune response to viral infection ${ }^{57}$. Isg15 or Interferon-stimulated gene 15 is a secreted cytokine and has intracellular function like ubiquitin, ISG15 is covalently linked by a C-terminal motif on newly-synthesized proteins, a process 
called ISGylation mediating both activation and inhibition of antiviral immunity ${ }^{58}$ although viral resistance is mediated in mice but not humans ${ }^{59}$. Trim28 is in the tripartite motif (TRIM) protein family, which is a group of E3 ligases implicated in the regulation of a variety of cellular functions including innate immunity to virus which may occur by viral protein degradation in proteasomes and TRIM28 may block transition from latent to lytic cycle ${ }^{60}$. TRIM28 also has a role in maintaining pluripotency through epigenetic regulation ${ }^{61}$ and is necessary to maintain epigenetic stability and imprinting during zygotic genome activation in mouse 2-cell stage embryos ${ }^{62}$. Although the phenotype is not the same as the ones studied here, the power of TRIM28 is reported in its role as the hierarchical epigenetic regulator of the complex polygenic, polyphenic cause of obesity, which TRIM28, depending on its wild type or haplo-insufficient activity, flips into an obese or non-obese state in isogenic animals that is dependent on the expression levels of a handful of imprinted genes ${ }^{63}$. TRIM28 is important in preventing provirus and endogenous retrovirus replication in ESC to protect germline lineage cells from insertional mutagenesis ${ }^{13}$. Interestingly, although most viral resistance genes decrease with stress, TRIM28 increases significantly with stress by both Pvalue and FDR (Supplemental Figure 2). Covid-19 is not a retrovirus as it does not rely on reverse transcriptase and a DNA intermediate for replication. On the other hand some Cov2 sequence has been detected in host cells, suggesting that the RNA genome is reverse transcribed into DNA at low frequency and small parts integrate into the genome ${ }^{64}$. Taken together viral resistance is decreased by stress, and for some genes the amount of viral resistance function with stress is less than basal NS state as well as the ND state. It will be important to establish whether these genes affect viral resistance to coronaviruses as reported for their viral resistance function for other viruses and whether they are expressed and mediate function in XEN lineage cells. The specific mechanisms of viral resistance in ESC and the subpopulations of cells that are resistant or susceptible due to these mechanisms, need to be tested. It will be important to test whether Covid-19 can infect ESC and/or XEN cells and whether insertional mutagenesis can affect the germ line of ESC genomes.

Four genes common to 3-4/4 negatively regulatory GO groups are also highly shared amongst all 15 host viral GO groups, but Bst2 and jun are not as highly shared. Genes highly shared amongst all 15 groups are: in 11/15 groups; oas1b and Isg15, in 9/15 groups; TRIM28, and in 7/15 groups; Krüppel-associated box zinc finger protein (Zfp809), Ifitm1, Nucleoporin 93 (Nup93), and nucleotide-binding oligomerization domain, leucine rich repeat containing X1 (NIrx1). New genes common to all 15 but not most shared in 4 negative regulatory are ZFP809,_NIrx1, and Nup93._ZFP809 can mediate epigenetic anti-retroviral effects through histone modification 
more than DNA methylation after sequence recognition of foreign DNA ${ }^{65}$. Endogenous retroviruses are silenced primarily by DNA methylation in somatic tissue but by $\mathrm{H} 3$ methylation (H3K9me3) in embryos and ESC ${ }^{66-68}$. NIrx1 found exclusively in the mitochondrial membrane, increases viral susceptibility by sequestering outer mitochondrial membrane proteins (MAVS) from another antiviral protein and thereby prevents mitochondrial antiviral immunity by preventing TBK1 to IRF3 to IFN $\beta$ transcription ${ }^{69}$. Nup93 is a nucleoporin that mediates mitochondrial activated TBK1 import to activate IRF3 and IFNB as part of innate immunity to retroviruses that NIrx1 blocks $^{70}$.

High stress at $300 \mathrm{mM}$ leads to high caspase 3 associated apoptosis in the first $12 \mathrm{hr}$ of stimulus but healthy cells with less than or about $5 \%$ death at $72 \mathrm{hr}$, whereas cell growth at $250 \mathrm{mM}$ is static and at $200 \mathrm{mM}$ significantly more cells accumulated at $72 \mathrm{hr}$ with a growth rate of about $75 \%$ at NS at $0 \%$ sorbitol ${ }^{21}$. At $200 \mathrm{mM}$ sorbitol only a third (5/15) of the GO groups significantly changed compared with all (15/15) groups at $300 \mathrm{mM}$ sorbitol. As expected, four fifths (4/5) of the significantly changed GO groups are in the top 5 highest significant changed groups at $300 \mathrm{mM}$ sorbitol and are changed in the same direction at $200 \mathrm{mM}$. Thus, the quality and direction of the response at $200 \mathrm{mM}$ is similar that at $300 \mathrm{mM}$ sorbitol but is less significant and of lower ranking. Loading controls of several categories suggested that the conclusions for counts per cell for different genes, number of genes expressed, and GO groups genes were solid interpretations. It is likely that in vivo highest stress may come from exposures to multiple stressors that synergize to create stress like $300 \mathrm{mM}$ sorbitol or higher.

The greatest loss of human life occurs soon after fertilization, as the early embryo begins exponential growth and implants into the uterus to access maternal nutrition ${ }^{54,71,72}$. Just before implantation, embryonic stem cells and placental trophoblast stem cells arise in the embryo and have the capability of forming all $200+$ cell types in adult humans and 10 lineages of the placenta, respectively. Viruses can harm the placenta or cross the placenta and infect the embryo or fetus: either of these events can have long term health risks for the fetus and offspring ${ }^{73}$. The first key problem here is that stress induces several coronavirus receptors including TMPRSS2, Dpp4, Anpep and Enpep, and stress induces ACE2 in some XEN lineages. The second problem is that host resistance genes that are expressed in normal stemness and increase with normal unstressed differentiation, decrease with stress; Oas1b, Isg15, Jun, Ifitm1, Bst2, Tspan7, Fam111a, and Eif2ak2. Taken together these data suggest that stress may lead to viral entry into first lineage XEN cells. This could lead to embryo death due 
to lack of sufficient XEN function ${ }^{16}$. But, although Covid-19 does not require reverse transcriptase and a replicative DNA intermediate that might insert into the host genome at high rates, there have been reports of Covid19 gene sequences in host genomic DNA ${ }^{64}$. These could be passed along to offspring and become transgenerational as $1^{\text {st }}$ lineage XEN cells have been shown to revert into totipotent 2-cell embryo like cells ${ }^{74}$ characteristic of the early post-fertilization embryo.

Key data suggest that maternal stress hormones sensitize the early post-implantation embryos and its ESC and TSC lineages to bisphenol A, leading to higher rates of miscarriage than either stressor alone ${ }^{75}$. Both types of stem cells in the implanting embryos respond to maternal stress hormones (adrenaline, cortisol) by growing more slowly ${ }^{54}$ and other stressors such as benzopyrene of bisphenyl A slow growth and exacerbate stress hormone caused embryo loss in vivo ${ }^{76}$. Viral infectivity of 5 viruses was shown to be proportional to the amount of psychological stress and independent of other immune factors such as white blood cell counts ${ }^{1}$, suggesting a focus stress-induced changes on viral receptors as a means to susceptibility. The data presented here support the hypothesis that stress can increase viral susceptibility by increasing receptor expression, but also suggest that stress can decrease host viral resistance, compounding Cov2 pathogenic potential in the early post-fertilization embryo around the time of embryo implantation into the uterus. Direct testing whether ESC and their early differentiated progeny can be infected is needed, and whether this leads to lineage imbalance or genetic or epigenetic changes. It is also important to test whether environmental stressors, not just control hyperosmotic stress can change susceptibility of the ESC lineage.

\section{Acknowledgements}

Thanks to members of our lab for analysis and comments on the manuscript. Thanks to Summer interns Tanmai Nimmagadda and Munsir Jabir for analysis and assembly of Excel databases. Thanks to Dr William Robert Fleischmann, Jr and to Anthony Maxwell for comments on the manuscript Dr Rappolee is funded by NIH 1R41ES028991-01, 1R41ES031451-01A1, P30 ES020957/CURES Pilot, and the Michigan Emerging Technology Fund. Dr. Ruden is funded by UH3 OD023285, S10 OD025170. 
Declarations before References

Funding (information that explains whether and by whom the research was supported)

This research was supported by grants to DAR from NIH (1R41ES028991-01, 1R41ES031451-01A1, P30 ES020957, grants to DMR: UH3 OD023285, S10 OD025170, CURES Pilot Michigan Emerging Technology Fund).

Conflicts of interest/Competing interests (include appropriate disclosures)

The authors have no conflicts of interest.

Ethics approval (include appropriate approvals or waivers)

Not applicable as no human or animal subjects were used.

Consent to participate (include appropriate statements)

No human subjects were used in the studies reported here and thus consent to participate is not applicable.

Consent for publication (include appropriate statements)

All authors have consented to submission of this manuscript

Availability of data and material (data transparency)

All data are available for communication or inspection

Code availability (software application or custom code)

No codes were created for these studies, all software and analysis were from software in the public domain or freely accessible.

\section{Authors' contributions}

Dr Abdulhasan, yes

Design of the work; data acquisition, data analysis, data interpretation

Ms Ruden, no

Mr Rappolee no

Dr S. Dutta no

Dr K Gurdziel no

Dr DM. Ruden no

yes

yes

yes

no yes no

no yes no

Dr AO. Awonuga no

Dr S. Korzeniewski yes

Dr EE. Puscheck no

Dr DA Rappolee yes

no

no yes

no yes yes

no yes yes

no no yes

no yes yes

no yes yes

yes yes yes 


\section{Bibliography}

1. Cohen S, Tyrrell DA, Smith AP. Psychological stress and susceptibility to the common cold. N Engl J Med 1991;325:606-12.

2. Gordon DE, Jang GM, Bouhaddou M, et al. A SARS-CoV-2 protein interaction map reveals targets for drug repurposing. Nature 2020;583:459-68.

3. Cyranoski D. Profile of a killer: the complex biology powering the coronavirus pandemic. Nature 2020;581:22-6.

4. Weatherbee BAT, Glover DM, Zernicka-Goetz M. Expression of SARS-CoV-2 receptor ACE2 and the protease TMPRSS2 suggests susceptibility of the human embryo in the first trimester. Open Biol 2020;10:200162.

5. Ashary N, Bhide A, Chakraborty P, et al. Single-Cell RNA-seq Identifies Cell Subsets in Human Placenta That Highly Expresses Factors Driving Pathogenesis of SARS-CoV-2. Front Cell Dev Biol 2020;8:783.

6. Pique-Regi R, Romero R, Tarca AL, et al. Does the human placenta express the canonical cell entry mediators for SARS-CoV-2? Elife 2020;9.

7. Colaco S, Chhabria K, Singh N, et al. Expression of SARS-CoV-2 receptor ACE2 and the spike protein processing enzymes in developing human embryos. arXIV 2020.

8. Zhou Y, Hou Y, Shen J, et al. A Network Medicine Approach to Investigation and Population-based Validation of Disease Manifestations and Drug Repurposing for COVID-19. ChemRxiv 2020.

9. Wang R, Simoneau CR, Kulsuptrakul J, et al. Genetic Screens Identify Host Factors for SARS-CoV-2 and Common Cold Coronaviruses. Cell 2020.

10. Gordon DE, Hiatt J, Bouhaddou M, et al. Comparative host-coronavirus protein interaction networks reveal pan-viral disease mechanisms. Science 2020;370.

11. Qi F, Qian S, Zhang S, Zhang Z. Single cell RNA sequencing of 13 human tissues identify cell types and receptors of human coronaviruses. Biochemical and Biophysical Research Communications 2020;526:135-40.

12. Yu YT, Chien SC, Chen IY, et al. Surface vimentin is critical for the cell entry of SARS-CoV. J Biomed Sci 2016;23:14. 
502 13. Yang BX, El Farran CA, Guo HC, et al. Systematic identification of factors for provirus silencing in embryonic stem cells. Cell 2015;163:230-45.

14. Wu X, Kwong AC, Rice CM. Antiviral resistance of stem cells. Curr Opin Immunol 2019;56:50-9.

15. Foulger RE, Osumi-Sutherland D, Mclntosh BK, et al. Representing virus-host interactions and other multi-organism processes in the Gene Ontology. BMC Microbiol 2015;15:146-.

16. Rappolee DA. It's not just baby's babble/Babel: recent progress in understanding the language of early mammalian development: a minireview. Mol Reprod Dev 1999;52:234-40.

17. Li Q, Yang Y, Louden E, Puscheck E, Rappolee D. High throughput screens for embryonic stem cells; stress-forced potency-stemness loss enables toxicological assays. In: Faqi A, ed. Methods In Toxicology and Pharmacology: Springer; 2016.

18. Li Q, Gomez-Lopez N, Drewlo S, et al. Development and Validation of a Rex1-RFP Potency Activity Reporter Assay That Quantifies Stress-Forced Potency Loss in Mouse Embryonic Stem Cells. Stem Cells Dev 2016;25:320-8.

19. Doetschman TC, Eistetter H, Katz M, Schmidt W, Kemler R. The in vitro development of blastocystderived embryonic stem cell lines: formation of visceral yolk sac, blood islands and myocardium. Journal of embryology and experimental morphology 1985;87:27-45.

20. Masui S, Ohtsuka S, Yagi R, Takahashi K, Ko MS, Niwa H. Rex1/Zfp42 is dispensable for pluripotency in mouse ES cells. BMC Dev Biol 2008;8:45.

21. Slater JA, Zhou S, Puscheck EE, Rappolee DA. Stress-induced enzyme activation primes murine embryonic stem cells to differentiate toward the first extraembryonic lineage. Stem Cells Dev 2014;23:3049-64.

22. Andrews S. FastQC A Quality Control Tool for High Throughput Sequence Data. 2010.

23. Dobin A, Davis CA, Schlesinger F, et al. STAR: ultrafast universal RNA-seq aligner. Bioinformatics 2013;29:15-21.

24. Anders S, Pyl PT, Huber W. HTSeq--a Python framework to work with high-throughput sequencing data. Bioinformatics 2015;31:166-9.

25. Robinson MD, McCarthy DJ, Smyth GK. edgeR: a Bioconductor package for differential expression analysis of digital gene expression data. Bioinformatics 2010;26:139-40. 
529 26. Huang W, Sherman BT, Lempicki RA. Systematic and integrative analysis of large gene lists using DAVID bioinformatics resources. Nature protocols 2009;4:44-57.

27. Wu YJ, Wang $\mathrm{H}$, Liang JH, et al. Using the geometric mean fluorescence intensity index method to measure ZAP-70 expression in patients with chronic lymphocytic leukemia. Onco Targets Ther 2016;9:797805.

28. Li Q, Louden E, Zhou J, et al. Stress Forces First Lineage Differentiation of Mouse Embryonic Stem Cells; Validation of a High-Throughput Screen for Toxicant Stress. Stem Cells Dev 2019;28:101-13.

29. Smith A. Formative pluripotency: the executive phase in a developmental continuum. Development 2017; 144:365-73.

30. Kalkan T, Olova N, Roode M, et al. Tracking the embryonic stem cell transition from ground state pluripotency. Development 2017;144:1221-34.

31. Munoz Descalzo S, Rue P, Garcia-Ojalvo J, Martinez Arias A. Correlations between the levels of Oct4 and Nanog as a signature for naive pluripotency in mouse embryonic stem cells. Stem Cells 2012;30:2683-91. 32. Chen H, Aksoy I, Gonnot F, et al. Reinforcement of STAT3 activity reprogrammes human embryonic stem cells to naive-like pluripotency. Nat Commun 2015;6:7095.

33. Han X, Wang R, Zhou Y, et al. Mapping the Mouse Cell Atlas by Microwell-Seq. Cell 2018;173:1307.

34. Klein AM, Mazutis L, Akartuna I, et al. Droplet barcoding for single-cell transcriptomics applied to embryonic stem cells. Cell 2015;161:1187-201.

35. Abdulhasan M, Dutta S, Gurdziel K, et al. Validating a high throughput screen using embryonic stem cells: transcriptomic analysis identifies unique aspects of stress-forced cellular adaptation. Cells 2021 ;in preparation.

36. Bennett JE, Dolin R, Blaser MJ. Mandell, Douglas, and Bennett's principles and practice of infectious diseases. Eighth edition. ed. Philadelphia, PA: Elsevier/Saunders; 2015.

37. Barrass SV, Butcher SJ. Advances in high-throughput methods for the identification of virus receptors. Medical Microbiology and Immunology 2019.

38. Mestecky J. Mucosal immunology. 3rd ed. Amsterdam ; Boston: Elsevier Academic Press; 2005.

39. Pillay S, Carette JE. Hunting Viral Receptors Using Haploid Cells. Annual Review of Virology 2015;2:219-39. 
40. Artus J, Panthier JJ, Hadjantonakis AK. A role for PDGF signaling in expansion of the extra-embryonic endoderm lineage of the mouse blastocyst. Development 2010;137:3361-72.

41. Abdulhasan M, Dutta S, Li Q, et al. Validating a high throughput screen using embryonic stem cells: transcriptomic analysis identifies stress-forced developmental adaptation. Stem Cell Research 2021 ;in preparation.

42. Morrisey EE, Tang Z, Sigrist K, et al. GATA6 regulates HNF4 and is required for differentiation of visceral endoderm in the mouse embryo. Genes Dev 1998;12:3579-90.

43. Koutsourakis M, Langeveld A, Patient R, Beddington R, Grosveld F. The transcription factor GATA6 is essential for early extraembryonic development. Development 1999;126:723-32.

44. Moein S, Javanmard SH, Abedi M, Izadpanahi MH, Gheisari Y. Identification of Appropriate Housekeeping Genes for Gene Expression Analysis in Long-term Hypoxia-treated Kidney Cells. Adv Biomed Res 2017;6:15.

45. Curina A, Termanini A, Barozzi I, et al. High constitutive activity of a broad panel of housekeeping and tissue-specific cis-regulatory elements depends on a subset of ETS proteins. Genes Dev 2017;31:399-412. 46. Eisenberg E, Levanon EY. Human housekeeping genes, revisited. Trends Genet 2013;29:569-74. 47. Yasunaga M, Tada S, Torikai-Nishikawa S, et al. Induction and monitoring of definitive and visceral endoderm differentiation of mouse ES cells. Nat Biotechnol 2005;23:1542-50.

48. Kinoshita M, Shimosato D, Yamane M, Niwa H. Sox7 is dispensable for primitive endoderm differentiation from mouse ES cells. BMC Dev Biol 2015;15:37.

49. Artus J, Douvaras P, Piliszek A, Isern J, Baron MH, Hadjantonakis AK. BMP4 signaling directs primitive endoderm-derived XEN cells to an extraembryonic visceral endoderm identity. Dev Biol 2012;361:245-62.

50. Rugg-Gunn PJ, Cox BJ, Lanner F, et al. Cell-surface proteomics identifies lineage-specific markers of embryo-derived stem cells. Dev Cell 2012;22:887-901.

51. Paca A, Seguin CA, Clements M, et al. BMP signaling induces visceral endoderm differentiation of XEN cells and parietal endoderm. Dev Biol 2012;361:90-102.

52. Kunath T, Arnaud D, Uy GD, et al. Imprinted X-inactivation in extra-embryonic endoderm cell lines from mouse blastocysts. Development 2005;132:1649-61. 
53. Seguin CA, Draper JS, Nagy A, Rossant J. Establishment of endoderm progenitors by SOX transcription factor expression in human embryonic stem cells. Cell Stem Cell 2008;3:182-95.

54. Puscheck EE, Awonuga AO, Yang Y, Jiang Z, Rappolee DA. Molecular biology of the stress response in the early embryo and its stem cells. Adv Exp Med Biol 2015;843:77-128.

55. Sakuma T, Noda T, Urata S, Kawaoka Y, Yasuda J. Inhibition of Lassa and Marburg virus production by tetherin. J Virol 2009;83:2382-5.

56. Feeley EM, Sims JS, John SP, et al. IFITM3 inhibits influenza A virus infection by preventing cytosolic entry. PLoS pathogens 2011;7:e1002337-e.

57. Green R, Wilkins C, Thomas S, et al. Oas1b-dependent Immune Transcriptional Profiles of West Nile Virus Infection in the Collaborative Cross. G3 (Bethesda) 2017;7:1665-82.

58. Woods MW, Kelly JN, Hattlmann CJ, et al. Human HERC5 restricts an early stage of HIV-1 assembly by a mechanism correlating with the ISGylation of Gag. Retrovirology 2011;8:95-.

59. Speer SD, Li Z, Buta S, et al. ISG15 deficiency and increased viral resistance in humans but not mice. Nature communications 2016;7:11496-.

60. van Tol S, Hage A, Giraldo MI, Bharaj P, Rajsbaum R. The TRIMendous Role of TRIMs in Virus-Host Interactions. Vaccines (Basel) 2017;5:23.

61. Oleksiewicz U, Gładych M, Raman AT, et al. TRIM28 and Interacting KRAB-ZNFs Control SelfRenewal of Human Pluripotent Stem Cells through Epigenetic Repression of Pro-differentiation Genes. Stem cell reports 2017;9:2065-80.

62. Messerschmidt DM, de Vries W, Ito M, Solter D, Ferguson-Smith A, Knowles BB. <em $>$ Trim28</em> Is Required for Epigenetic Stability During Mouse Oocyte to Embryo Transition. Science 2012;335:1499-502.

63. Dalgaard K, Landgraf K, Heyne S, et al. Trim28 Haploinsufficiency Triggers Bi-stable Epigenetic Obesity. Cell 2016;164:353-64.

64. Zhang L, Richards A, ., Khalil A, et al. SARS-CoV-2 RNA transcribed and integrated into the human genome. bioRxiv 2020.

65. Wolf G, Yang P, Füchtbauer AC, et al. The KRAB zinc finger protein ZFP809 is required to initiate epigenetic silencing of endogenous retroviruses. Genes \& development 2015;29:538-54. 
611 66. Mikkelsen TS, Ku M, Jaffe DB, et al. Genome-wide maps of chromatin state in pluripotent and lineagecommitted cells. Nature 2007;448:553-60.

67. Rebollo R, Romanish MT, Mager DL. Transposable elements: an abundant and natural source of regulatory sequences for host genes. Annu Rev Genet 2012;46:21-42.

68. Wolf G, Yang P, Fuchtbauer AC, et al. The KRAB zinc finger protein ZFP809 is required to initiate epigenetic silencing of endogenous retroviruses. Genes Dev 2015;29:538-54.

69. O'Neill LA. Innate immunity: squelching anti-viral signalling with NLRX1. Curr Biol 2008;18:R302-4.

70. Monwan W, Kawasaki T, Hasan MZ, Ori D, Kawai T. Identification of nucleoporin 93 (Nup93) that mediates antiviral innate immune responses. Biochem Biophys Res Commun 2020;521:1077-82.

71. Yang Y, Bolnick A, Shamir A, et al. Blastocyst-Derived Stem Cell Populations under Stress: Impact of Nutrition and Metabolism on Stem Cell Potency Loss and Miscarriage. Stem Cell Rev 2017;13:454-64.

72. Yang Y, Abdulhasan M, Awonuga A, Bolnick A, Puscheck EE, Rappolee DA. Hypoxic Stress Forces Adaptive and Maladaptive Placental Stress Responses in Early Pregnancy. Birth Defects Res 2017;109:133044.

73. Racicot K, Mor G. Risks associated with viral infections during pregnancy. The Journal of clinical investigation 2017;127:1591-9.

74. Sharova LV, Sharov AA, Piao Y, et al. Emergence of undifferentiated colonies from mouse embryonic stem cells undergoing differentiation by retinoic acid treatment. In vitro cellular \& developmental biology Animal 2016;52:616-24.

75. Borman ED, Foster WG, Greenacre MKE, Muir CC, deCatanzaro D. Stress lowers the threshold dose at which bisphenol A disrupts blastocyst implantation, in conjunction with decreased uterine closure and ecadherin. Chemico-Biological Interactions 2015;237:87-95.

76. Borman ED, Foster WG, Greenacre MK, Muir CC, deCatanzaro D. Stress lowers the threshold dose at which bisphenol A disrupts blastocyst implantation, in conjunction with decreased uterine closure and ecadherin. Chem Biol Interact 2015;237:87-95.

77. Bernardo AS, Jouneau A, Marks $\mathrm{H}$, et al. Mammalian embryo comparison identifies novel pluripotency genes associated with the naive or primed state. Biol Open 2018;7. 
638 78. Martello G, Sugimoto T, Diamanti E, et al. Esrrb is a pivotal target of the Gsk3/Tcł3 axis regulating 639 embryonic stem cell self-renewal. Cell Stem Cell 2012;11:491-504.

640 79. Weinberger L, Ayyash M, Novershtern N, Hanna JH. Dynamic stem cell states: naive to primed

641 pluripotency in rodents and humans. Nat Rev Mol Cell Biol 2016;17:155-69.

642 80. Kalkan T, Bornelov S, Mulas C, et al. Complementary Activity of ETV5, RBPJ, and TCF3 Drives

643 Formative Transition from Naive Pluripotency. Cell Stem Cell 2019;24:785-801 e7.

644 81. Kim HJ, Osteil P, Humphrey SJ, et al. Transcriptional network dynamics during the progression of 645 pluripotency revealed by integrative statistical learning. Nucleic Acids Res 2020;48:1828-42.

646

647

648

649

650

651

652

653

654

655

656

657

658

659

660

661

662

663 
Figure1. Paradigm: 72hr exposure of embryonic stem cells (ESC) - grown in culture as stem cells - will identify stress levels that override growth and stemness and create teratogenic and epigenetic changes that persist and affect health. Terminology: we compare three states of ESC - normal stemness (NS) normal differentiation (ND) and the override; stress-forced differentiation (SFD). SFD is given at three doses that create normal growth to negative growth at this highest dose of positive control hyperosmotic. +control stress is hyperosmotic sorbitol at three doses. 6.5 in vivo and in ESC in vitro from previous cited studies (in parentheses); 1$)^{-77} 3$ core"0" or initiating naïve pluripotency (NS) genes downstream of LIF receptor: Stat3, Klf4, Tbx3 with 5 other naïve genes Tcf3, Nanog, Essrb,Pou5F1,and an additional 2 Gjb5, Scpep $1{ }^{78}$ 2) ten $2^{\text {nd }}$ lineage formative pluripotency genes: Dusp6, Trip6, Lin28b ${ }^{78}$, Otx2, Zic2 ${ }^{79}$ CD47, Sox11, Egr1, Dnmt3b $29,30,80,81$, 3) Epha4a 3-three $3^{\text {rd }}$ lineage "primed" plu-

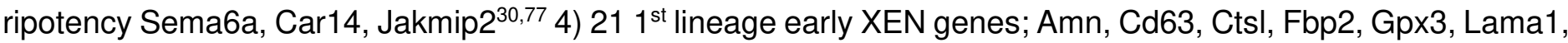
Gsn, Lpar3, Lrpap1, Man2c1, P4ha2, PGK1, Col4a1/2, Podxl, S100a10, Serpinh1, SIc2a3, Sparc, Srgn, Tfp1 ${ }^{34}$ 5) $201^{\text {st }}$ lineage late XEN genes; Amn, Cd63, Ctsl, Clu, Ctsh, Lama1, EPAS1, Fst,Gata4/6, Lamb1, Lrpap1, P4ha2, Ph4b, Col4a1/2, Pga5, Serpinh1,,Sparc, Upp1 $\left.{ }^{34}\right)$ 6) $151^{\text {st }}$ lineage XEN genes AFP, Gata4, Sox17, Lamb1, Lama1, Aqp8, Vim, Plac1, Rhox6/9, Emp2, TROMA/krt8, Col4a1/2, Amn ${ }^{33}$ ), for lineages 0/1/2/3, and 7) Eighteen Aerobic glycolysis and Warburg genes; Slc2a1/Glut1, HK1, Pfkfb3, PGI-GPI, PFK1, Aldoa/c, Tpi1, Gapdh, PGK1,PGAM1, ENO1, PKM2, LDHA/B, PDH1, PDK1, SLc16a3-MCT435 Starting “0” ESC lineage (E3.5- 
4.5) is Naïve pluripotent stem cells or NS from figure 1, $1^{\text {st }}$ lineage from NS pluripotency is extraembryonic endoderm/XEN and later lineages are restrictions of Naïve stemness: $2^{\text {nd }}$ lineage formative pluripotency (E5.5) and $3^{\text {rd }}$ lineage primed pluripotency. (B) The majority of genes in 4 viral negative regulatory groups increase from NS to ND, blocking viral pathogenesis, but gene expression in most genes in these groups reverses with SFD $300 \mathrm{mM}$ sorbitol compared with ND. (C) 6 coronavirus and 3 known transplacental susceptibility genes were studied, and upregulation or downregulation are indicated by fold change and significance by Pvalue and FDR. (D) A diagram of pre-implantation blastocyst at E4.5 (4.5 days after fertilization) and post-implantation embryo at E5.5 and near the start of gastrulation at E6.25. In the terminology of this figure, the $0^{\text {th }}$ lineage is ICM/ESC at E4.5 which is naïve pluripotency/NS, $1^{\text {st }}$ lineage is XEN arising before implantation, $2^{\text {nd }}$ lineage is ND/formative pluripotency and $3^{\text {rd }}$ lineage is primed pluripotency just before the start of gastrulation.

Figure 3 Stress changes expression for 6 host ESC genes for Coronavirus susceptibility, 8 genes for known transplacentally-transmitted virus susceptibility and 1 additional virus of highly significant changed susceptibility for virus uptake. These are single genes analyzed from bulk RNAseq for counts $X_{+} /$-SD for ESC cultured under NS for 72hr, and then FC (green increase and red decrease) for ND/NS and for SFD highest dose at 300mM sorbito/ND and then SFD highest dose/NS. Blue indicates significant FC between one culture treatment to another. On the far- right Green highlights indicate Coronavirus and yellow indicates trans-placentally-transmitted virus.

Figure 4. First differentiated lineage XEN cells increase with $300 \mathrm{mM}$ sorbitol stress as much as positive control XEN morphogen retinoic acid, and first lineage mouse and human ESC differentiated to first lineage by culture conditions of Sox17 transgenic overexpression, cause induction of ACE2 and Tmprss2 Covid19 susceptibility genes. (A) Pdgfra-GFP ESC were exposed to $72 \mathrm{hr}$ LIF+ (NS), LIF- (ND), 1uM retinoic acid a normal morphogen for $1^{\text {st }}$ lineage XEN induction from ESC or $200-400 \mathrm{mM}$ sorbitol in the presence of LIF to test for a stress dose that causes similar $\%$ of bright and intermediate bright $1^{\text {st }}$ lineage Pdgfra+ cells as assayed by flow cytometry ${ }^{28}$ , (B) Three mouse ESC lines were culture under conditions to maintain stemness (far right) or XEN differentiation (3 histogram bars on left) and tested for ACE2, Tmprss2 Covid19 susceptibility genes or Gata6 XEN determining transcription factor, from NCBI GEO database; GSM40110/22/23/24 ${ }^{52}$. (C) Two human ESC lines were culture 
under conditions to maintain stemness (2 histogram bars on far right) or two human ESC lines transdifferentiated to XEN differentiation using first lineage driver Sox17 (2 histogram bars on left) and tested for ACE2, Tmprss2 Covid19 susceptibility genes or Gata6 XEN determining transcription factor, from NCBI GEO database; GSM2722918/19/20/2153

Figure 5 Fifteen Viral GO groups were significant for stress induced fold changes in host ESC host-viral genome interactome genome rank of significance when comparing ND culture to NS culture but mostly SFD culture compared with NS or ND culture and 15 other viral host interactome GO Groups were not significant. (A) 15 host viral GO groups for virus interaction had increasing significance at 300mM SFD compared with ND from top to bottom. Bottom two rows show total GO groups and significant GO groups for a comparison of culture ESC treatments.

Figure 6. Loading controls from highest copy number (A) and from previously published reviews (B). For ESD we typically use GAPDH, ACTB, and 18 S loading controls which report high copy number RNA from ribosomes. Red shows decreasing expression from NS, green shows increasing expression from NS, pink shows ribosomeassociated genes with names indicated in footnotes at the bottom, blue shows significance, orange shows order of ranking by highest expression in ESC at $300 \mathrm{mM}$ sorbitol and dark green is expression of the same genes as NS or OmM sorbitol culture.

Supplemental figure 1. More comprehensive list of stress effects on viral receptor gene expression includes Viruses listed by WHO as highest priority (https://www.who.int/activities/prioritizing-diseases-for-research-anddevelopment-in-emergency-contexts), List of Wiki virus list (https://en.wikipedia.org/wiki/Virus).

Supplemental figure 2. (A) Comprehensive analysis of all genes expressed in all 15 significant host viral interaction GO groups. Includes X+/-SD for Counts during NS ESC culture, ND/NS FC ratio of mean counts, SFD/ND FC ratio of mean counts, and SFD/NS FC ratio of mean counts.

(B) Ninety-one genes expressed in the 15 groups were analyzed here for how many GO groups each gene is listed in. 
(C) Twenty-one genes expressed uniquely in one GO group.

(D) Ten genes important in provirus silencing and suppression of endogenous ret-

750 rovirus transposition ${ }^{13}$.

751 Supplemental figure 3. Low ranking host viral GO groups which were not significant when comparing $300 \mathrm{mM}$ 752 sorbitol SFD to ND. (associated with Figure 6A) 
Figures

Embryonic stem cell - Rex1-RFP, Pdgfra-GFP High throughput screen (HTS) Passage $\rightarrow$ Tzero $\rightarrow$ Tfinal 3 SFD doses

\begin{tabular}{lllll}
\hline 0 & 200 & 250 & 300 & Sorbitol $(\mathrm{mM})$ \\
Exponential & Good & Static & Negative & Proliferation
\end{tabular}

\section{Experimental Overview}

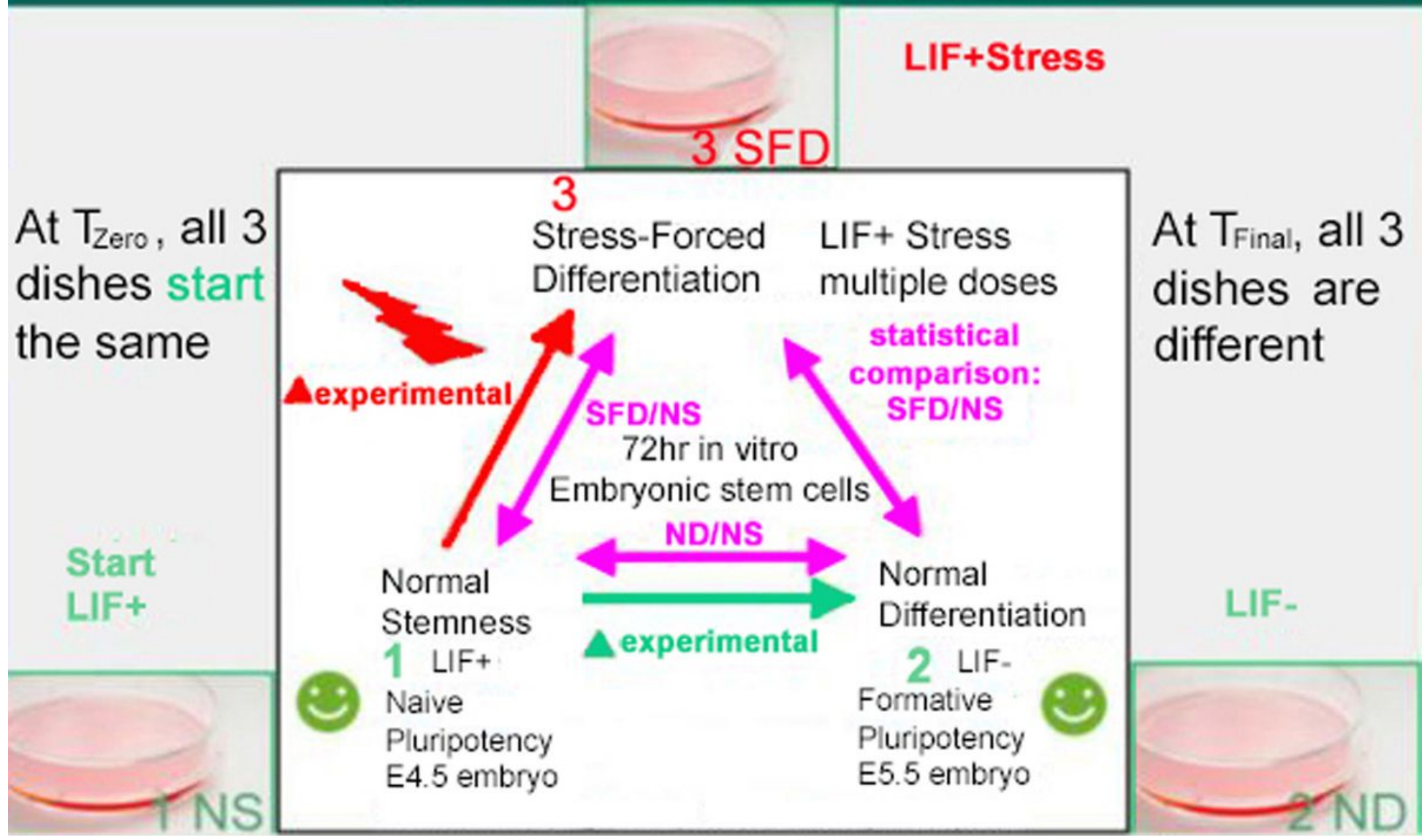

Figure 1

Please see the manuscript file to view the figure caption. 
Embryo age (post-fert)

E4.5 1st diff. lineage - XEN - 15 genes

E4.5 1st diff. lineage - XEN - 21 early 1 day genes

E4.5 1st diff. lineage - XEN - 20 late 4-7day genes

E3.5-45 Oth lineage, Naive pluripotency core 3 genes

E3.5-45 Oth lineage, Naive pluripotency 8 marker genes

E5.5 2nd lineage, Formative pluripotency 10 genes

E6.25

Increases E4.5-6.5 Markers aerobic glycolysis Warburg 18 genes

Viral 16 genes GO:0046597 negative regulation of viral entry into host cell(15) $\mathbf{B}$

GO 16 genes GO:0048525 negative regulation of viral process

GO:1903901 negative regulation of viral life cycle

GO:0045071 negative requlation of viral genome replication



total significant significant

\begin{tabular}{ll|ll} 
ND/NS (\%) & ND/NS (\%) & SFD/ND & SFD/ND
\end{tabular}

(33) A $10 / 5 / 15(67 \%) \quad 4 / 0 / 4(100 \%) \quad 11 / 4 / 15(73 \%) \quad 6 / 2 / 8(75 \%)$

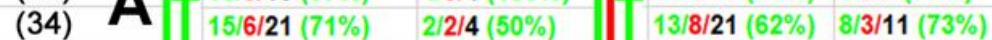

\begin{tabular}{l|ll|l|l|} 
(34) & $13 / 7 / 20(65 \%)$ & $0 / 3 / 3(100 \%)$ & $17 / 3 / 20(85 \%)$ & $8 / 2 / 10(80 \%)$
\end{tabular}

(76) $\mid$\begin{tabular}{ll|l|l|}
$13 / 3(100 \%)$ & $0 / 3 / 3(100 \%)$ & $3 / 0 / 3(100 \%)$ & $3 / 0 / 3(100 \%)$
\end{tabular}

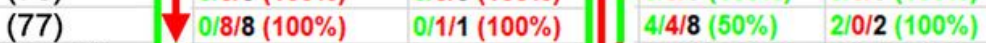

$(2930,78) \quad 7 / 3 / 10(70 \%) \quad 4 / 1 / 5(80 \%) \quad-3 / 7 / 10(70 \%) \quad 2 / 5 / 7(71 \%)$

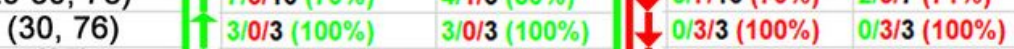

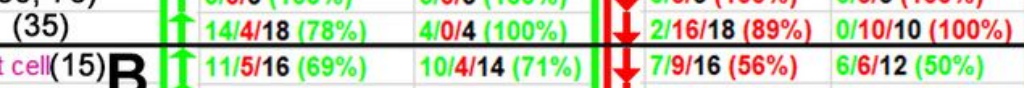

$\begin{array}{ll}11 / 5 / 16(69 \%) & 3 / 2 / 5(60 \%) \\ 6 / 10 / 16(63 \%) & 6 / 10 / 16(63 \%)\end{array}$

\begin{tabular}{ll|l|l|l|l|l|}
\hline $5 / 1 / 6(83 \%)$ & $5 / 1 / 6(83 \%)$ & \multicolumn{1}{|c}{$2 / 4 / 6(67 \%)$} & $1 / 3 / 4(75 \%)$
\end{tabular}

\begin{tabular}{ll|ll}
$7 / 4 / 11(64 \%)$ & $0 / 1 / 1(100 \%)$ & \multicolumn{3}{|c|}{$3 / 8 / 11(83 \%)$} & $3 / 8 / 11(83 \%)$
\end{tabular}

\begin{tabular}{|l|l|l|l|}
\hline FC ND/NS & FC SFD/ND & \\
\hline 2.1 & 4.6 & significant
\end{tabular}

\begin{tabular}{|c|c|c|c|}
\hline 2.1 & & 4.6 & significant \\
\hline-1.7 & significant & 3.1 & significant \\
\hline 0 & & 0 & \\
\hline 1.7 & & 3.4 & \\
\hline 3.9 & & 1 & significant \\
\hline 3.3 & & -2.8 & \\
\hline 1.2 & & 4.5 & significant \\
\hline 1.1 & & 1.9 & \\
\hline 1.5 & & 1.2 & \\
\hline
\end{tabular}

Figure 2

Please see the manuscript file to view the figure caption.

\begin{tabular}{|c|c|c|c|c|c|c|}
\hline \multicolumn{3}{|c|}{$\begin{array}{l}\text { Naiive pluripotency } \\
\text { Normal stemness }\end{array}$} & \multicolumn{4}{|c|}{$\begin{array}{l}\text { Formative pluripotency } \\
\text { Normal differentiation }\end{array}$} \\
\hline $\begin{array}{l}\text { Viral } \\
\text { Receptor }\end{array}$ & $\begin{array}{l}\text { NS } \\
\text { Counts }\end{array}$ & & $\begin{array}{l}\text { Viral } \\
\text { Receptor }\end{array}$ & ND vs NS & & \\
\hline Gene & $\mathrm{x}$ & $S D$ & Gene & Fold Change & PValue & FDR \\
\hline Tmprss2 & 1 & 1 & Tmprss2 & 2.087582525 & 0.27992 & 1 \\
\hline Vim & 41 & 18.2 & Vim & -1.69560349 & 0.06753 & 1 \\
\hline Ace2 & 0 & 0 & Ace2 & -1 & 1 & 1 \\
\hline DPP4 & 2 & 1 & Dpp4 & 1.682067259 & 0.41625 & 1 \\
\hline Anpep & 1 & 0.5 & Anpep & 3.263007828 & 0.22242 & 1 \\
\hline ENPEP & 0 & 0 & Enpep & 3.861329928 & 0.25606 & 1 \\
\hline Haver1 & 0 & 0 & Haver1 & -1 & 1 & 1 \\
\hline Pvrl1 & 10 & 4.4 & Pvrl1 & 1.169125638 & 0.6763 & 1 \\
\hline PDGFRA & 1.7 & 2.1 & Pdgfra & 1.071379406 & 0.92879 & 1 \\
\hline EGFR & 6 & 3 & Egfr & 1.517187199 & 0.23639 & 1 \\
\hline Hn1 & 291 & 176.7 & Hn1 & -1.04872437 & 0.80021 & 1 \\
\hline PVR & 19.1 & 8.2 & PVR & 1.177230264 & 0.55541 & 1 \\
\hline Mog & 0 & 0 & Mog & -1 & 1 & 1 \\
\hline pvrl4 & 1.7 & 0.6 & Pvrl4 & 2.605888289 & 0.15236 & 1 \\
\hline St3gal4 & 8 & 2.6 & St3gal4 & -1.51460822 & 0.31822 & 1 \\
\hline
\end{tabular}



Increasing Decreasing Significant Stress-forced differentiation Viral SFD vs ND
Viress-forced differentiation NStoND Receptor

vs. SFD Gene Fold Change PValue FDR Gene

in kind Tmprss2 reversal Vim

in kind Ace2 in kind Dpp4 reversal Anpep in kind Enpep

reversal Havcr1 in kind Pvrl1 in kind Pdgfra in kind Egfr reversal Hn1 reversal Pvr reversal Mog reversal Pvr14 reversal St3gal4 Stress-forced differentiation Viral SFD vs NS Receptor

Coronavirus Fetal Exposure Known transplacental viruses




$\begin{array}{llllllll}-1 & 1 & 1 & \text { Ace2 } & -1 & 1 & 1 & \text { Covid1/SARS Covid2 }\end{array}$ \begin{tabular}{lll|l|l|l|l|l|l}
3.419998887 & 0.02527 & 0.22634 & Dpp4 & 5.752668152 & 0.00301 & 0.06203 & Covid1/SARS Covid2
\end{tabular} $\begin{array}{lllllllll}-2.8464626 & 0.28006 & 0.73567 & \text { Anpep } & 1.146337854 & 0.90224 & 1 & \text { MERS }\end{array}$ \begin{tabular}{llll|lll|l}
1.020853863 & 0.98636 & 1 & Enpep & 3.941853573 & 0.25093 & 0.73924 & Mammalian coronaviruses
\end{tabular}

55.40502405 7.01E-05 3.39E-03 Havcr1 55.40502405 5.90E-05 4.21E-03 Hepatitis A 4.478391584 1.11E-05 8.27E-04 Pvrl1 5.235802419 1.94E-06 3.07E-04 Herpex simplex virus $1 \mathrm{HSV} 1$

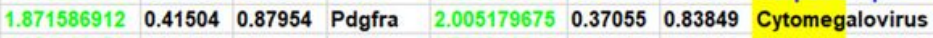
$\begin{array}{lllllllll}1.121841471 & \mathbf{0 . 7 2 3 2 2} & \mathbf{1} & \text { Egfr } & 1.702043519 & \mathbf{0 . 1 2 4 9 8} & \mathbf{0 . 5 5 4 0 2} & \text { Cytomegalovirus }\end{array}$ $\begin{array}{lllllllll}-1.8339746 & 0.0016 & 0.0349 & \text { Hn1 } & -1.92333386 & 0.00066 & 0.0231 & \text { Mumps virus }\end{array}$ \begin{tabular}{llllll|l|l|l|l}
-1.92810155 & 0.02641 & 0.2319 & Pvr & -1.63782873 & 0.09962 & 0.50068 & Poliovirus
\end{tabular}

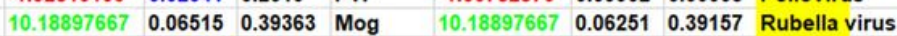
$\begin{array}{lllllllllll}-5.68496653 & 0.02217 & 0.20947 & \text { Pvrl4 } & -2.18158489 & 0.35218 & 0.81653 & \text { Measles virus }\end{array}$ $\begin{array}{lllllllll}1.293484023 & 0.5414 & 1 & \text { St3gal4 } & -1.1709524 & 0.69327 & 1 & \text { Zika virus }\end{array}$ 
Please see the manuscript file to view the figure caption.
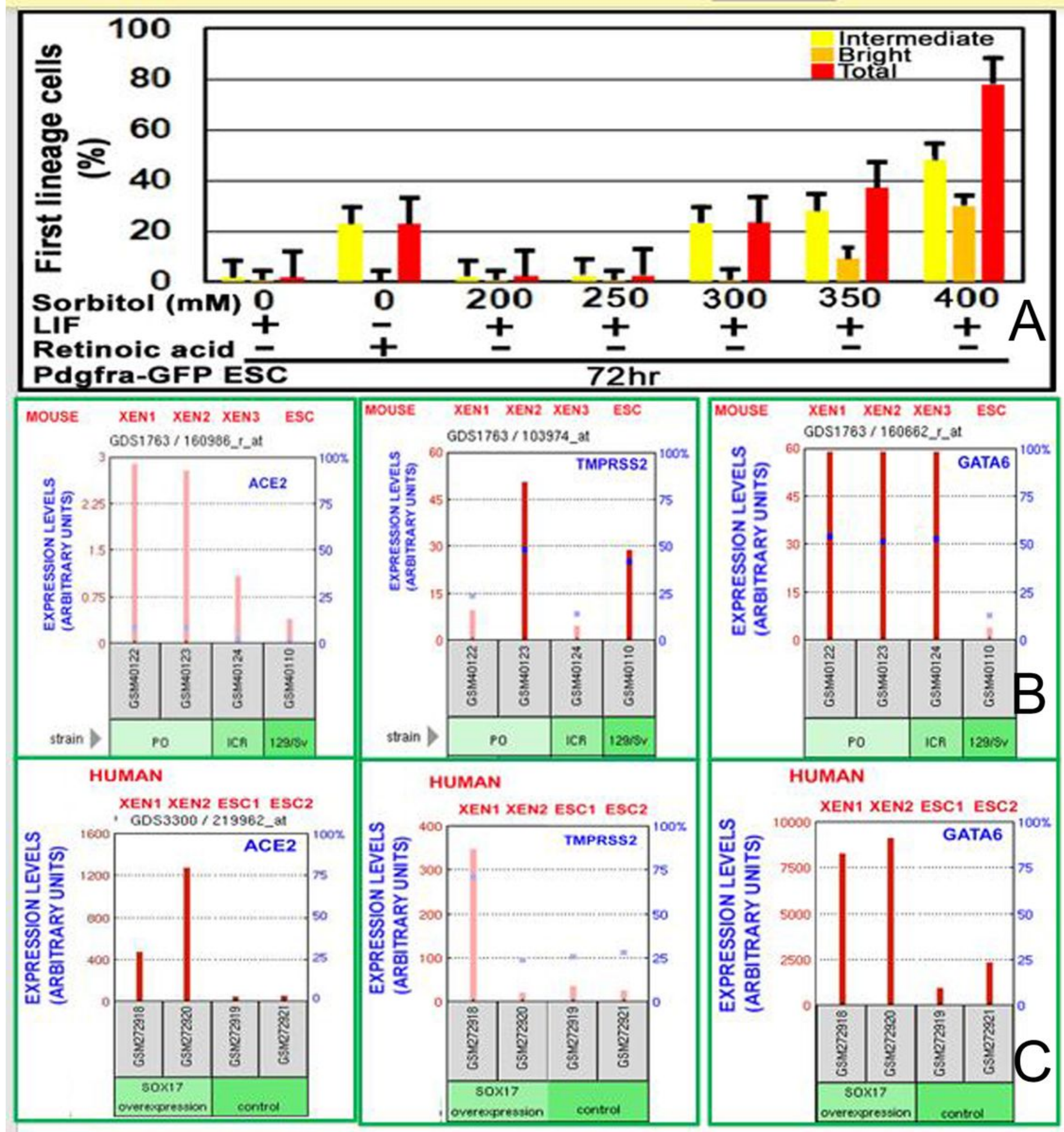

Figure 4

Please see the manuscript file to view the figure caption. 
GO Group: change in expression of genes, significance rank of group, \% rank, and significance

Gene expression change (mostly $\uparrow$ )

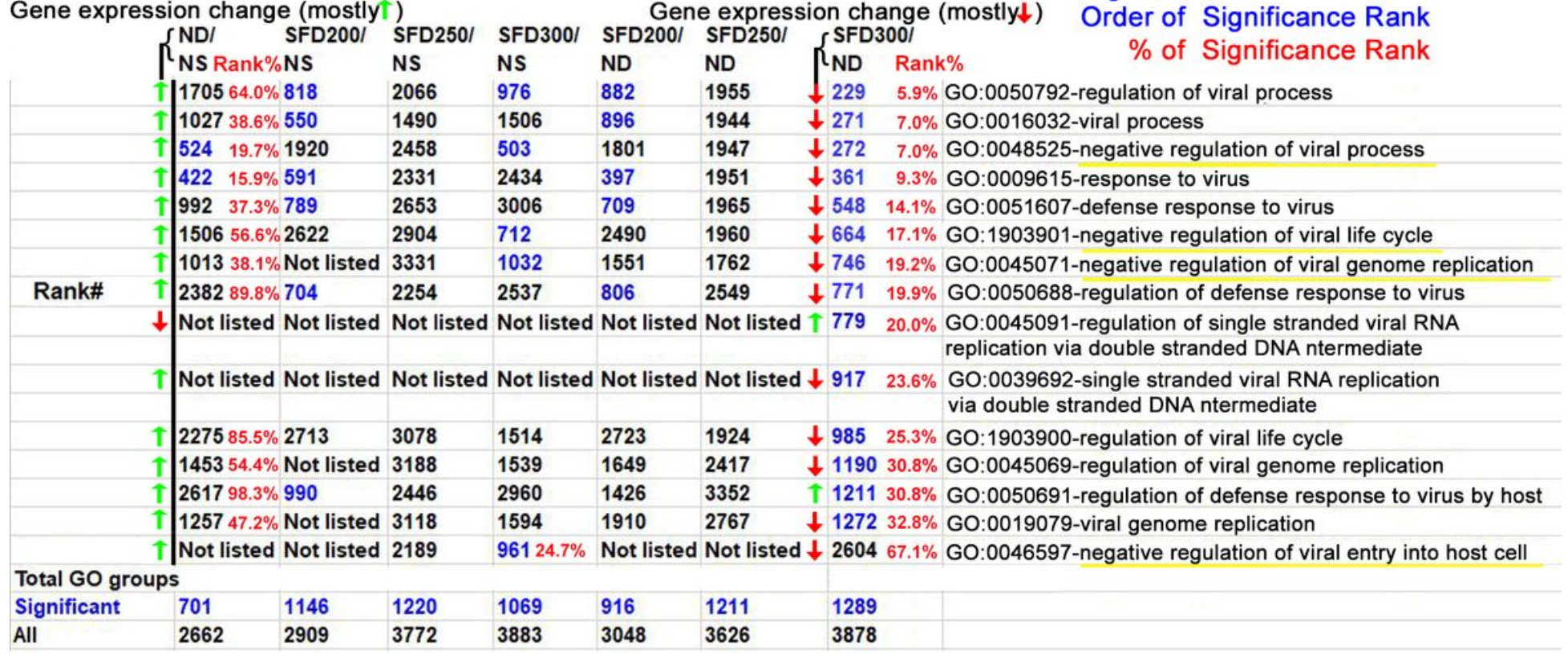

Figure 5

Please see the manuscript file to view the figure caption. 
Pluripotency

\begin{tabular}{|c|c|c|c|c|c|}
\hline Eif2s2 & -1.17 & 0.46 & 0.94 & 21307.33 & 16723.66 \\
\hline Aps 14 & 1.018 & 0.94 & 1 & 13802.66 & 13475.33 \\
\hline Hsp90ab1 & -1.28 & 0.27 & 0.74 & 18920.66 & 13423.33 \\
\hline Actb & 1.078 & 0.72 & 1 & 11941.33 & 12056.66 \\
\hline Gnb211 & -1.06 & 0.77 & 1 & 8837.66 & 8178.66 \\
\hline Aps 12 & 1.21 & 0.29 & 0.74 & 6849.66 & 8131.33 \\
\hline Rps20 & -1.3 & 0.14 & 0.58 & 11778.66 & 7536.33 \\
\hline Rpl23a & 1.01 & 0.95 & 1 & 7381.66 & 7371.33 \\
\hline Rps21 & 1.37 & 0.13 & 0.56 & 5350 & 7338.66 \\
\hline Aplp2 & 1.50 & 0.03 & 0.26 & 5135.66 & 7301 \\
\hline Rpl8 & -1.25 & 0.29 & 0.74 & 9315.66 & 6570.66 \\
\hline Fus & 1.12 & 0.68 & 1 & 5790.33 & 5653 \\
\hline Prds1 & 1.07 & 0.70 & 1 & 4900 & 5302 \\
\hline Aps 3 & 1.22 & 0.31 & 0.76 & 4341.33 & 5260.33 \\
\hline Serbp1 & 1.06 & 0.75 & 1 & 5261.33 & 5256 \\
\hline Hsp90aa1 & -1.49 & 0.08 & 0.46 & 8484.33 & 5154.33 \\
\hline Aplp1 & 1.33 & 0.26 & 0.73 & 3593.33 & 4931 \\
\hline Sod1 & -1.45 & 0.08 & 0.47 & 7761.33 & 4912.66 \\
\hline Rps5 & -1.28 & 0.22 & 0.72 & 6850.6 & 4894.33 \\
\hline Tuba1b & 2.17 & 0.00 & 0.02 & 2359 & 4853 \\
\hline
\end{tabular}

EIF2S2 is an intiatinge protein elongation factor that binds IRNA to 40 S ribosomal subunits RPS are 405 structural ribosomal proteins

RPLP are 60 structural acidic proteins

RPL are 605 ribosomal structural proteins

GNB2L UPACK1 is a ribosomal 405 subunit binding protein

Serbp1 interacts with GNB2LIIRACK1 and the ribosomal 405 subunit

\begin{tabular}{|c|c|c|c|c|c|c|c|c|c|c|c|c|c|c|c|}
\hline \multirow{3}{*}{$\begin{array}{l}\text { Gene } \\
\text { ACTB }\end{array}$} & \multicolumn{3}{|c|}{ Normal stemness } & \multicolumn{4}{|c|}{ Normal differentiation ND/NS } & \multicolumn{4}{|c|}{ Stress-forced differentiation SFD/ND } & \multicolumn{3}{|c|}{ Stress-forced differentiation } & \multirow{2}{*}{$\begin{array}{l}\text { SFD/NS } \\
\text { FDR }\end{array}$} \\
\hline & $\mathrm{x}$ & SD & gene & Fold Change & PValu & FDR & & gene & Fold Change & PValue & FDR & gene & Fold Change & PValue & \\
\hline & 11941.3 & 7805.87 & Actb & -1.26 & 0.26 & 1 & reversal & Actb & 1.36 & 0.13 & 0.57 & Actb & 1.07 & 0.72 & 1 \\
\hline GAPDH & 130.7 & 177 & Gapdh & 2.24 & 0.12 & 1 & reversal & Gapdh & -1.60 & 0.36 & 0.81 & Gapdh & 1.40 & 0.51 & 0.99 \\
\hline Pgk1 & 19.7 & 22.9 & Pgk1 & 1.10 & 0.87 & 1 & reversal & Pgk1 & -2.00 & 0.29 & 0.73 & Pgk1 & -1.80 & 0.36 & 0.83 \\
\hline Ppia & 61.7 & 76.8 & Ppia & -1.24 & 0.70 & 1 & reversal & Ppia & 1.71 & 0.34 & 0.80 & Ppia & 1.37 & 0.57 & 1 \\
\hline RPLP0 & 2352.67 & 1389.73 & Rplp0 & 1.15 & 0.48 & 1 & reversal & Rplp0 & -1.19 & 0.38 & 0.84 & Rplp0 & -1.03 & 0.86 & 1 \\
\hline B2M & 17.66 & 7.37 & $\mathrm{~B} 2 \mathrm{~m}$ & 1.23 & 0.56 & 1 & reversal & $\mathrm{B} 2 \mathrm{~m}$ & -2.01 & 0.06 & 0.38 & $\mathrm{~B} 2 \mathrm{~m}$ & -1.63 & 0.19 & 0.67 \\
\hline YWHAZ & 878.66 & 554.58 & Ywhaz & -1.19 & 0.38 & 1 & reversal & Ywhaz & -1.10 & 0.63 & 1 & Ywhaz & -1.31 & 0.17 & 0.64 \\
\hline Sdha & 258 & 98.7 & Sdha & 1.03 & 0.85 & 1 & reversal & Sdha & -1.12 & 0.53 & 1 & Sdha & -1.08 & 0.65 & 1 \\
\hline TFRC & 319.66 & 106.64 & Tfrc & 1.07 & 0.74 & 1 & reversal & Tfrc & -1.14 & 0.54 & 1 & Tfrc & -1.06 & 0.78 & 1 \\
\hline GUSB & 15 & 7.810 & Gusb & 1.06 & 0.82 & 1 & in kind & Gusb & 1.19 & 0.54 & 1 & Gusb & 1.27 & 0.40 & 0.87 \\
\hline HMBS & 28 & 12.76 & Hmbs & 1.37 & 0.24 & 1 & in kind & Hmbs & 1.04 & 0.88 & 1 & Hmbs & 1.43 & 0.18 & 0.66 \\
\hline HPRT & 15.66 & 1.52 & Hprt & -1.63 & 0.24 & 1 & in kind & Hprt & -2.29 & 0.08 & 0.43 & Hprt & -3.74 & 0.00 & 0.07 \\
\hline TBP & 16 & 1.73 & Tbp & 1.20 & 0.58 & 1 & in kind & Tbp & 1.13 & 0.70 & 1 & Tbp & 1.37 & 0.35 & 0.82 \\
\hline
\end{tabular}

Figure 6

Please see the manuscript file to view the figure caption.

\section{Supplementary Files}

This is a list of supplementary files associated with this preprint. Click to download. 
- Graphicalabstract482021.pdf

- Supplementalfigure1472021.xlsx

- Supplementalfigure2472021.xlsx

- Supplementalfigure3472021.jpg 